\title{
Peach (Prunus persica L. Batsch) production and environmental conditions in Jenin, Palestine
}

\author{
Jehad M. H. Ighbareyeh ${ }^{1 *}$, Mohammed M. H. Ighbareyeh ${ }^{1}$, Asma A. A. Suliemieh ${ }^{1}$, Abdel- $^{2}$ \\ Qader Daraweesh ${ }^{1}$, Cano Carmona $E^{2}$ and Ana Cano Ortiz ${ }^{2}$ \\ ${ }^{1}$ Department of Plant Production and Protection, Faculty of Agriculture, Al-Quds Open University, Abu Khatallah Street, \\ Hebron, Hebron, Palestine. \\ ${ }^{2}$ Department of Animal, Plant Biology and Ecology, University of Jaen, Jaen, Spain.
}

Accepted 27 May, 2019

\begin{abstract}
Peach is a fruit tree which contributes to the building of the agricultural and national economy of many countries of the world, including Palestine. Peach and nectarines are affected by the surrounding climatic conditions. In this study, meteorological data were taken from the meteorological station of the city of Jenin from the Palestinian meteorological stations in Ramallah. Data of climatic conditions and fruit production was recorded from the beginning of January 1993 to December 2012, from the Central Bureau of Statistics Palestinian conflict. The Salvador Rivas Martinez of the bioclimatic and the land classification program was used to the analysis of environmental factors. Then XLASTAT software program was used to determine the relationship between climate, bioclimate variables and peach production for the studied area. The principal component analysis and the correspondence analysis were used. Results showed that Jenin region was positively influenced by factors of precipitation, annual ombrothermic index, simple continentality index and soil water reserve, because these factors sited at the positive X-axis during (1993-1996 and 2002-2007), and symmetric plot of axes (F1 and F2: 99.37\%) of the total variance. Our analysis showed that peach cultivation is adapted in areas where mean monthly temperatures are between 17 and $22^{\circ} \mathrm{C}$, simple continentality index (15 to 19), precipitation (450 to $1000 \mathrm{~mm}$ ), compensated thermicity index (250/350), and annual ombrothermic index is more than 2.5 at Jenin area of Palestine.
\end{abstract}

Keywords: Palestine, Jenin, Fertile Crescent, Marj Ibin Amer, peach, production, environmental.

*Corresponding author. Email: jehadighbareyeh@hotmail.com.

\section{INTRODUCTION}

Peach (Prunus persica L. Batsch) is a native tree of northwestern China between the Tarim Basin and the northern slopes of the Kunlun Mountains, where it was first planted (Faust and Timon, 2010). It is a deciduous tree belonging to the Rosaceae family. Peaches grow in a properly limited in temperate, continental or dry climates, that's trees have chilling requirements. Most varieties require 500 hours of chilling about 0 to $10^{\circ} \mathrm{C}(32$ to $50^{\circ} \mathrm{F}$ ). Peach play an important role in increasing the national economy and in achieving self-sufficiency and food security, along with some other fruit trees such as olives, grapes and almonds in Palestine (Ighbareyeh et al., 2014d, 2015c; Jehad et al., 2015h, 2016a,c, 2017a,c). Peaches and nectarine are stored at temperatures of $0^{\circ} \mathrm{C}$, with a high humidity. They are highly perishable and are usually consumed or packaged during the two weeks of harvesting date. Peaches are climacteric fruit which continue to maturity process after being harvested from the tree (Szalay et al., 2000; Trainotti et al., 2007; Ziosi et al., 2007).

Moreover, peaches are of economic importance in the world, so there is great demand for the cultivation of this important food and healthy crop world production of peaches and nectarines reached 25 million tons, where China produced $58 \%$ of total world production, followed by the European Union, Spain, Italy, United States and Iran (United Nations and FAOSTAT, 2018; FAOSTAT, 2016). In Palestine, peach yields are about $600 \mathrm{~kg}$ per dunum, while in Jenin it ranges from 300 to $500 \mathrm{~kg}$ per dunum annually (PCBS, 2007; Ighbareyeh et al., 2015h; 
Ighbareyeh and Cano Carmona, 2017c). Peaches and almonds production areas are concentrated in southern Palestine, specifically the Hebron area, due to the suitable climate and the fertile soil (Jehad et al., 2015h). In the last few years, many researchers in the Mediterranean region, especially in Palestine, Italy and Spain, have studied the impact of many climatic variables on plant production, plant sustainability and growth (Cano-Ortiz et al., 2014; Leiva et al., 2017; Ighbareyeh et al., 2014a, c, d, 2015a, b, c, d, e, g, i, 2016b, d, 2017b, 2018c, d, e; Ighbareyeh, 2019; Ighbareyeh and Cano Carmona, 2018a, b). The purpose of this study is to determine the impact of climatic and bioclimatic factors on peach production and to adopt this study within the plans, strategies and policies of the Palestinian Ministry of Agriculture in order to promote the Palestinian economy and achieve food security in Palestine.

\section{METHODOLOGY}

\section{Area study}

Jenin is located in the north of Palestine, $75 \mathrm{~km}$ away to the north of Jerusalem, overlooks the Jordan Valley to the east and Marj bin Amer (which is considered the most fertile land of historic Palestine) to the north (Figure 1), an area of 21,000 dunums, making it the third largest Palestinian city in the West Bank after Hebron and Nablus. Jenin is $583 \mathrm{~km}^{2}$, or 9.7 percent of the total West Bank, it is located at 32.28 North latitude and 35.18 east of Greenwich, and $175 \mathrm{~m}$ above sea level (Shahin, 2005; Ighbareyeh et al., 2015h).

\section{Plant and meteorology data resources and its analysis}

In this study, we analyzed the data recorded for temperature and precipitation from 1993 to 2012, which were obtained from the meteorological station of the city of Jenin (http://www.pmd.ps/englishlndexPage.do) (Figure 2), and then analyzed these data by using the Salvador Rivers Martins classification of land (Rivas-Martinez et al., 1996, 2004, 2005, 2008; Rivas-Martinez et al., 1999, 2011, 2017). On the other hand, we take same data of peach production (dependent variable) of the Jenin area from the Palestinian Central Bureau of Statistics (http://www.pcbs.gov.ps/).

Independents variables were included: Climate variables as mean monthly temperature $(T)$, precipitation $(P)$ and soil water reserve $(\mathrm{R})$; others bioclimatic factors as annual ombrothermic index (lo), compensated thermicity index (It/ltc), simple continentality index (Ic) and water deficit (Df) as presented in the (Table 1). The XLASTAT software program was used to determine the relationship between independents variables and plant production. Jarque-Bera and Shapiro-Wilk normality tests were used to perform statistical analysis (Jarque and Bera, 1980, 1987; Shapiro and Wilk, 1965; Shapiro et al., 1968), and the probability value for all variables was obtained. The analysis of variance (ANOVA) tests analysis were utilized for each independent variables, and peach production. The correspondence analysis (CA), the principal component analysis, the correlation matrix Pearson (n), and the factor loading analysis were performed to define the impact of differences variables on peach yield.
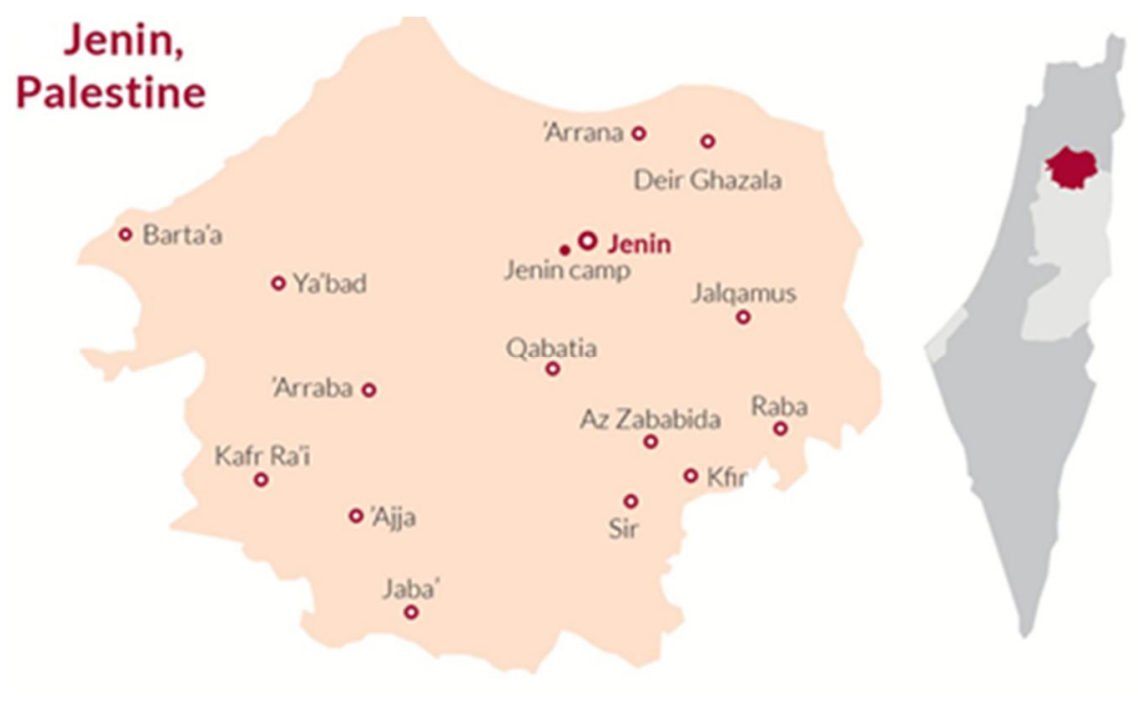

Figure 1. Study area, including Jenin station.

\section{RESULTS}

\section{Factor extraction analysis}

Principal components analysis (PCA) is a statistical proceeding that uses a perpendicular shift to convert a set of observations of possible correlated variables into a set of variables that are not linearly linked and called principal components, invented by Pearson (1901), as a counterpart to the theory of the main axis of mechanics; and developed it independently later by Harold Hoteling in (1933). It is the simplest of the valid eigenvector 


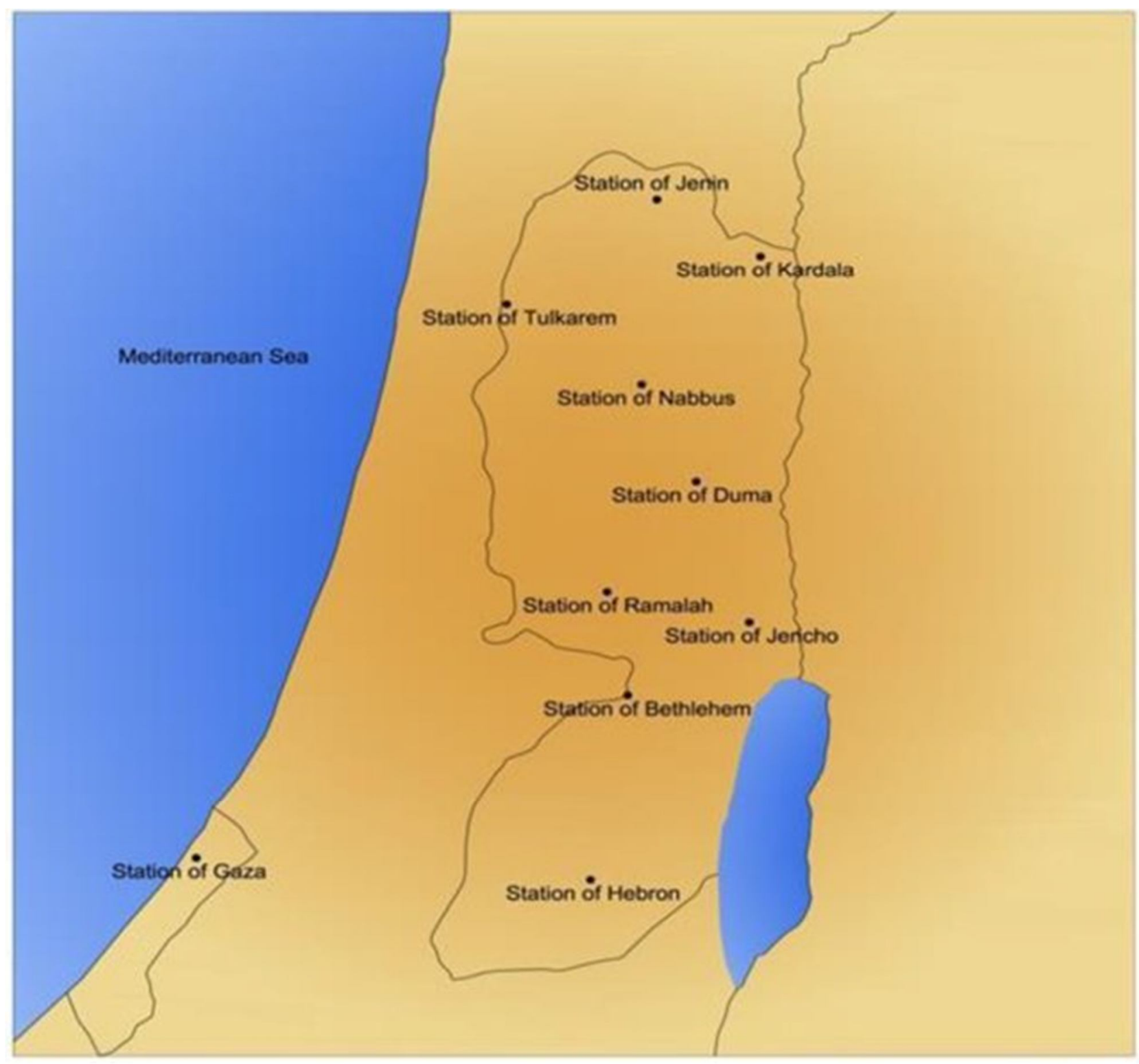

Figure 2. Some Palestinian meteorological stations, including Jenin.

Table 1. Peach production and meteorology data from 1993 - 2012.

\begin{tabular}{lcccccccc}
\hline Years & T & P & Df & R & Itc & Ic & lo & Peach production \\
\hline $1993-1996$ & 20 & 498 & 761 & 400 & 450 & 17.9 & 2.1 & 523 \\
$1996-2002$ & 21.4 & 477 & 788 & 420 & 477 & 17.6 & 1.88 & 496 \\
$2002-2007$ & 22.5 & 466 & 769 & 455 & 487 & 17.3 & 1.79 & 467 \\
$2007-2012$ & 23 & 470 & 796 & 388 & 456 & 17 & 1.57 & 501 \\
\hline
\end{tabular}

dependent on multivariate analysis. However, correspondence analysis (CA) is a multivariate statistical model proposed by Hirschfeld (1935), and subsequent developed by Benzécri (1973), it is theoretically similar to the principal component analysis.

\section{Factor loading analysis}

Factor loads are coefficients that exist either in a matrixstyle factor or a matrix-structure factor (Osborne et al., 2008). PCA is a widely used way of extracting factors, 
and it's the first stage of exploratory factor analysis (Polit and Beck, 2012). PCA was used to help determine the real eigenvector, depending on multivariate analysis, after varimax rotation the extraction factor can be used with the eigenvalue $>1$. PCA consequence, with factor loading and varimax rotation as well as eigenvalues, were presented in (Table 2), and three of the eigenvalues were existed to be $>1$ (Figure 3 ), and the total variance of the two factors (F1 and $F 2$ ) was about (99.37\%) (Figure 4 ), and the probability value was obtained from the variables result less than 0.05 , a traditionally acceptable value.

Nevertheless, factor 1 was dominated by mean monthly temperature (0.019557), soil water reserve (0.054938) and compensated thermicity index (0.027352), but its negatively by the reset of variables, and accounting for $(80.89 \%)$ of the total variance and accumulative as in the (Table 2) and (Figure 4). Factor 2 was dominated by rainfall $(0.01622)$, soil water reserve $(0.014636)$, simple continentality index (0.014439), and annual ombrothermic index (0.094665); and factor 3 was dominated by mean monthly temperature $(0.022651)$ and precipitation $(0.000983)$, while it was negative with the rest of the other factors.

\section{Correlation matrix Pearson ( $\mathrm{n}$ )}

In Pearson correlation coefficient is referred to Pearson $\mathrm{R}$, that is a statistical mode that measures the force between variables and relationships, to determine the strength between of these relationships and variables, to detection the coefficient value, which can reach between -1.00 to 1.00 (Pearson,1895, 1901; Wright, 1921; Stigler,1989), and a correlation matrix is a table that shows correlation coefficients between variable sets, where 1 is total positive linear correlation, and -1 is total negative linear correlation, and 0 is no linear correlation. However In the analysis process using the correlation coefficient Pearson, it was found that all correlation coefficients were between 1 and 1 , indicating a positive and negative linear relationship, which in turn affects peach production as shown in Table 3.

\section{DISCUSSION}

Otherwise, during the application of principal component analysis and correspondence analysis (CA), Jenin region was a positive influenced by factors of annual ombrothermic index, precipitation, simple continentality index and soil water reserve, because these factors sited at the positive X-axis during (1993-1996 and 2002-2007) and symmetric plot of axes F1 and F2: $99.37 \%$ of the total variance, this is a positive indicator of peach production and plant sustainability, whilst negatively influenced by the factors of mean monthly temperature, deficit water and compensated thermicity index (Figure 4).
Table 2. Principal component analysis with factor loading analysis.

\begin{tabular}{lccc}
\hline Variables & F1 & F2 & F3 \\
\hline $\mathrm{T}$ & 0.019557 & -0.04654 & 0.022651 \\
$\mathrm{P}$ & -0.02134 & 0.01622 & 0.000983 \\
$\mathrm{Df}$ & -0.00609 & -0.01961 & $-7.6 \mathrm{E}-06$ \\
$\mathrm{R}$ & 0.054938 & 0.014636 & 0.002047 \\
$\mathrm{Itc}$ & 0.027352 & -0.00465 & -0.00368 \\
$\mathrm{lc}$ & -0.00873 & 0.014439 & -0.00342 \\
lo & -0.02377 & 0.094665 & -0.02665 \\
Peach of production & -0.04211 & 0.008435 & $4.68 \mathrm{E}-05$ \\
Eigenvalue & 0.001024 & 0.000234 & $7.92 \mathrm{E}-06$ \\
Inertia (\%) & 80.89024 & 18.48444 & 0.625321 \\
Cumulative \% & 80.89024 & 99.37468 & 100 \\
\hline
\end{tabular}

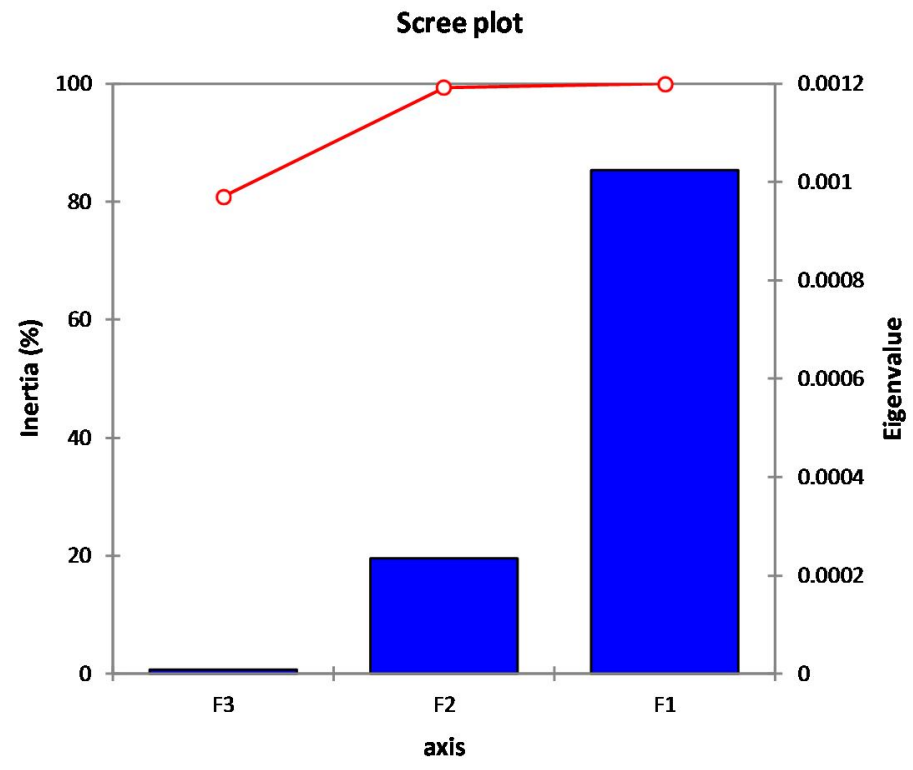

Figure 3. Component loadings in principal component analysis.

However, in the factor loading analysis (Table 2), peach production has been positive influenced by the factors mean monthly temperature, soil water reserve, and compensated thermicity index, because these factors have a positive value and dominated in the analysis, in contrast to the rest of the other factors as in the F1, noting that there is a difference in the impact of climate and bio-climate factors on the peach production for the $\mathrm{F} 1, \mathrm{~F} 2$ and F3 in the process of analysis. As a rule, water drainage (soil water reserve) in the soil has a positive effect on the production of peaches, this confirms that the soil is suitable and optimal for peach cultivation, wellventilated and with an ideal acidity as $\mathrm{pH}$ 5-7 (6.5 optimal), therefore, when using the principal component analysis and correspondence analysis, climatic and bioclimatic factors were also positive, with the exception of the average temperature as in F1 and F3, while some 


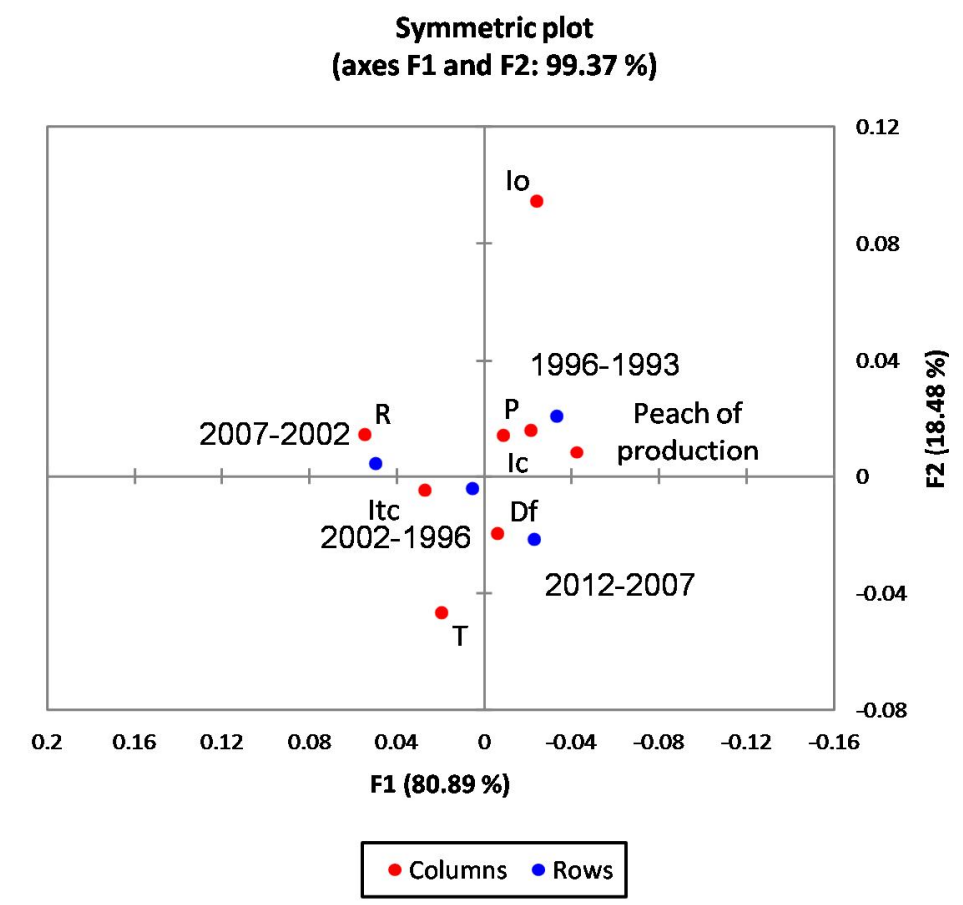

Figure 4. Correspondence analysis and principal component analysis of peach plant.

Table 3. Pearson correlation matrix.

\begin{tabular}{lcccccccc}
\hline Variables & $\mathbf{T}$ & $\mathbf{P}$ & $\mathbf{D f}$ & $\mathbf{R}$ & Itc & Ic & lo & Peach p. \\
\hline T & 1 & -0.944 & 0.648 & 0.178 & 0.397 & -0.980 & -0.964 & -0.682 \\
P & -0.944 & 1 & -0.555 & -0.454 & -0.674 & 0.861 & 0.844 & 0.862 \\
Df & 0.648 & -0.555 & 1 & -0.380 & 0.012 & -0.683 & -0.787 & -0.097 \\
R & 0.178 & -0.454 & -0.380 & 1 & 0.915 & 0.004 & 0.083 & -0.840 \\
Itc & 0.397 & -0.674 & 0.012 & 0.915 & 1 & -0.208 & -0.178 & -0.910 \\
Ic & -0.980 & 0.861 & -0.683 & 0.004 & -0.208 & 1 & 0.988 & 0.532 \\
lo & -0.964 & 0.844 & -0.787 & 0.083 & -0.178 & 0.988 & 1 & 0.470 \\
Peach of production & -0.682 & 0.862 & -0.097 & -0.840 & -0.910 & 0.532 & 0.470 & 1 \\
\hline
\end{tabular}

factors were negative on the production of peach in both the analysis of the principal component and factors loadings analysis, including water deficit and compensated thermicity index. Else, the analysis showed that there was a difference in the effect of climatic and bioclimatic factors such as mean monthly temperature, rainfall, simple continentality index and annual ombrothermic index, which showed a positive effect on peach production, unlike the other factors that showed a negative effect such as water deficit and compensated thermicity index as in the (Table 3), and this is another indication that there is a variance or significant that is traditionally consistent with the analysis of the study. Otherwise, it should be noted that climate and bioclimate plays an important role in determining the agricultural areas in Palestine and anywhere in the world, because the plants are produced in the areas where it can adapt to habitat. However, Jenin has rich and fertile soil (Fertile Crescent) and extended between the coast of Palestine and the Nile River in Egypt, it has the plain Marj bin Amer, which is one of the richest land of Palestine and the world.

\section{Conclusion}

Jenin region was influenced by factors of annual ombrothermic index, precipitation, simple continentality index and soil water reserve, unlike to the rest of factors as compensated thermicity index and water deficit. Moreover, in order to obtain optimum peach production, peach cultivation is required in areas where mean 
monthly temperatures are between 17 and $22^{\circ} \mathrm{C}$, precipitation (450 to $1000 \mathrm{~mm}$ ), simple continentality index (15 to 19), compensated thermicity index $(250 / 350)$, and annual ombrothermic index is more than 2.5. This corresponds to the Jenin area in northern occupied Palestine, whose climate is suitable for Mediterranean, and climate of the Mediterranean basin is a fertile and good environment for peach cultivation.

\section{REFERENCES}

Benzécri JP, 1973. L'Analyse des Données. Volume II. L'Analyse des Correspondances. Paris, France: Dunod.

Cano-Ortiz A, Ighbareyeh JMH, Cano E, 2014. Bioclimatic applications and soil Indicators for olive cultivation (south of the Iberian Peninsula). Glob Adv Res J Agric Sci, 3: 433-438.

FAOSTAT, 2016. Corporate Statistical Database almonds (in shells) production in 2016, Crops/Regions/World list/Production Quantity.

Faust M, Timon BL, 2010. Origin and Dissemination of Peach. Horticultural Reviews. p. 331.

Hirschfeld HO, 1935. A connection between correlation and contingency. Proc Cambridge Philosophical Soc, 31: 520-524.

Hoteling $H, 1933$. Analysis of a complex of statistical variables into principal components. J Educ Psychol, 24: 417-441.

Ighbareyeh J, Suliemieh A, Ighbareyeh M, Daraweesh A-Q, Ortiz AC, Cano Carmona E, 2018e. Impact of bioclimatic and climatic factors on Ficus carica L. yield: increasing the economy and maintaining the food security of Jerusalem in Palestine. Transylvanian Rev, 26(34): 8719 ,

Ighbareyeh JMH, 2019. Bioclimate of Jericho in Palestine. Palestine Technical Univ Res J, 7(1): 1-7.

Ighbareyeh JMH, Cano Carmona E, 2017c. Impact of climate and bioclimate factors on apricot (Prunus armeniaca L.) yield to increase economy and achieve maintaining food security of Palestine. Open Access Library J, 4: e4119

Ighbareyeh JMH, Cano Carmona E, 2018a. A phytosociological of plant communities and biodiversity in the East-South of Idna VillageHebron of Palestine. Int J Geosci, 9:44-58.

Ighbareyeh JMH, Cano Carmona E, 2018b. Impact of environment conditions on grapevine (Vitis vinifera L.): To optimal production and sustainability, achieving food security and increasing the Palestinian economy. J Geosci Environ Protect, 6: 62-73.

Ighbareyeh $\mathrm{JMH}$, Cano Carmona $\mathrm{E}$, Ortiz $\mathrm{AC}$, Ighbareyeh $\mathrm{MMH}$, Suliemieh AAA, 2018c. Grapevine (Vitis vinifera L.) yield and climate conditions of Palestine. Curr Sci, 114, 8.

Ighbareyeh JMH, Cano-Ortiz A, Cano Carmona E, 2014a. Biological and bioclimatic basis to optimize plant production: Increased economic areas of Palestine. Agric Sci Res J, 4: 10-20.

Ighbareyeh JMH, Cano-Ortiz A, Cano Carmona E, 2014b. Case Study: Analysis of the physical factors of Palestinian bioclimate. Am J Climate Change, 3: 223-231.

Ighbareyeh JMH, Cano-Ortiz A, Cano Carmona E, 2014d. Case study: Analysis of the physical factors of Palestinian bioclimate. Am J Climate Change, 3: 223-231.

Ighbareyeh JMH, Cano-Ortiz A, Cano Carmona E, 2015a. Study of biology and bioclimatology of date palm (Phoenix dactylifera L.) to optimize yield and increase economic in Jericho and Gaza Cities of Palestine. Int J Res Stud Biosci, 3: 1-8.

Ighbareyeh JMH, Cano-Ortiz A, Cano Carmona E, Ighbareyeh $\mathrm{MMH}$, Asma AA Suliemieh, 2015h. Modeling of biology and bioclimatology applied on plant in Palestine. Swift J Agric Res, 1: 21-27.

Ighbareyeh JMH, Cano-Ortiz A, Cano Carmona E, Ighbareyeh $\mathrm{MMH}$, Suliemieh AAA, Hijjeh S, 2017a. Impact of bioclimate and climate factors on plant yield in the area of Jenin at the north of Palestine. Int J Curr Res, 9: 44529-44535.

Ighbareyeh JMH, Cano-Ortiz A, Cano Carmona E, Ighbareyeh MMH, Suliemieh AAA, 2016b. Effect of biology, climatic and bioclimatic applied studies on plant: to increase the economy and maintaining food security in the Jerusalem Occupied of Palestine. Int J Res Stud Biosci, 4: 54-60.

Ighbareyeh JMH, Cano-Ortiz A, Suliemieh AAA, Ighbareyeh $\mathrm{MMH}$ Cano Carmona E, 2015c. Biology and bioclimatology applied on plant in Palestine. Int J Res Stud Biosci, 3: 79-86.

Ighbareyeh JMH, Cano-Ortiz A, Suliemieh AAA, Ighbareyeh $\mathrm{MMH}$, Cano Carmona E, 2016c. Modeling of biology and bioclimatology applied studies on plant in Palestine. Int J Dev Res, 6: 9585-9590.

Ighbareyeh JMH, Cano-Ortiz A, Suliemieh AAA, Ighbareyeh $\mathrm{MMH}$, Cano Carmona E, 2015g. Study of climatology and bioclimatology applied on plant in Area of Hebron in Palestine. Int Multidisciplinary Res J, 5(1): 2231-5063.

Ighbareyeh $\mathrm{JMH}$, Cano-Ortiz A, Suliemieh AAA, Ighbareyeh $\mathrm{MMH}$ Cano Carmona E, 2014c. Phytosociology with other characteristic biologically and ecologically of plant in Palestine. Am J Plant Sci, 5: 3104-3118.

Ighbareyeh JMH, Cano-Ortiz A, Suliemieh AAA, Ighbareyeh MMH, Cano Carmona E, 2015b. Assessment of biology and bioclimatology of plant to increase economy in Palestine. Int J Res Stud Biosci, 3: 1 8.

Ighbareyeh $\mathrm{JMH}$, Cano-Ortiz A, Suliemieh AAA, Ighbareyeh $\mathrm{MMH}$, Cano Carmona E, 2016a. Study of biology and bioclimatology applied on apricot (Prunus armeniaca L.): to increase the economy and maintaining food security in Palestine. Int $J$ Res Stud Biosci, 4:12-20.

Ighbareyeh JMH, Cano-Ortiz A, Suliemieh AAA, Ighbareyeh $\mathrm{MMH}$, Cano Carmona E, 2015d. Assessing crop yield sustainability under the climatic and bioclimatic change in the area of Palestine. Am J Climate Change, 4: 48-56.

Ighbareyeh JMH, Cano-Ortiz A, Suliemieh AAA, Ighbareyeh MMH, Cano Carmona E, 2015e. Study effect of biology and bioclimatology applied on plant in the Area of Hebron at the South of Palestine. Int $J$ Res Stud Biosci, 3: 56-64.

Ighbareyeh JMH, Cano-Ortiz A, Suliemieh AAA, Ighbareyeh $\mathrm{MMH}$, Cano Carmona E, 2015i. Effect of biology and bioclimatology applied studies on plant in the Area of Jerusalem in Palestine. Int J Res Stud Biosci, 3: 135-140.

Ighbareyeh JMH, Cano-Ortiz A, Suliemieh AAA, Ighbareyeh $\mathrm{MMH}$, Cano Carmona E, Hijjeh S, 2016d. Effect of bioclimate factors on olive (Olea europea L.) yield: To increase the economy and maintaining food security in Palestine. Int J Dev Res, 6: 1064810652.

Ighbareyeh JMH, Carmona EC, Ortiz AC, Suliemieh AAA, Ighbareyeh $\mathrm{MMH}$, Daraweesh AAM, 2018d. Analysis of physical factors of climate and bioclimate and their effects on almonds production to increase the economy in Hebron area of Palestine. Arab J Geosci, 11: 683 .

Ighbareyeh JMH, Cano-Ortiz A, Cano Carmona E, Suliemieh AAA, Ighbareyeh $\mathrm{MMH}, 2017 \mathrm{~b}$. Flora endemic rare and bioclimate of Palestine. Open Access Library J, 4:e3977.

Jarque C, Bera A, 1980. Efficient tests for normality homoscedasticity and serial independence of regression residuals. Econometric Lett, 6 : 255-259.

Jarque C, Bera A, 1987. A test for normality of observations and regression residuals. Int Stat Rev, 55: 163-172.

Leiva GF, Cano-Ortiz A, Musarella CM, Piñar Fuentes JC, Pinto Gomes CJ, Cano E, 2017. New method for increasing sustainable agricultural yield. Transylvanian Rev, 26(13): 3638-3648.

Osborne JW, Costello AB, Thomas Kellow J, 2008. Best Practices in Exploratory Factor Analysis, Chapter 6. DOI: https://dx.doi.org 10.4135/9781412995627.d8

PCBS, 2007. Agricultural Statistics - Miscellaneous Data. http://www.pcbs.gov.ps/pcbs_2012/Publications_AR.aspx.

Pearson K, 1895. Notes on regression and inheritance in the case of two parents. Proc Royal Soc London, 58: 240-242.

Pearson K, 1901. Philosophical Magazine, 2(11): 559-572.

Polit DF, Beck CT, 2012. Nursing Research: Generating and Assessing Evidence for Nursing Practice, 9th ed. Philadelphia, USA: Wolters Klower Health, Lippincott Williams \& Wilkins.

Rivas Martinez S, 1996. Clasificación bioclimática de la Tierra. Folia Bot. Matritensis., 16:1-20.

Rivas Martinez S, 2004. Worldwide Bioclimatic Classification System. www.globalbioclimatics.org. 
Rivas Martinez S, Sanchez Mata D and Costa M, 1999. North American boreal and western temperate forest vegetation (Syntaxonomical synopsis of the potential natural plant communities of North America, II). Itinera Geobot, 12: 5-316.

Rivas-Martinez S, 2005. Notions on dynamic-catenal phytosociology as a basis of landscape science. Plant Biosyst, 139(2):135-144.

Rivas-Martinez S, 2008. Global bioclimatic. http://www.globalbio climatics.org.

Rivas-Martínez S, Penas A, del Río S, Díaz González T, Rivas-Sáenz $S$, 2017. Bioclimatology of the Iberian Peninsula and the Balearic Islands. In: Loidi J. (eds) The Vegetation of the Iberian Peninsula. Plant and Vegetation, vol. 12 (1): 29-80. Springer, Cham.

Rivas-Martínez S, Rivas-Sáenz S, Penas A, 2011. Worldwide Bioclimatic Classification System. Global Geobotany, 1: 1-634.

Shahin M, 2005. Palestine: A Guide. Interlink Books p. 183.

Shapiro S, Wilk M, 1965. An analysis of variance test for normality (complete samples). Biometrika, 52: 591-611.

Shapiro S, Wilk M, Chen $\mathrm{H}, 1968$. A comparative study of various tests for normality. J Am Stat Assoc, 63: 1343-1372.

Stigler SM, 1989. Francis Galton's account of the invention of correlation. Stat Sci, 4(2): 73-79.

Szalay L, Papp J, Szaóbo Z, 2000. Evaluation of frost tolerance of peach varieties in artificial freezing tests. Acta Horticulturae, 538(538): 407-410.

Trainotti L, Tadiello A, Casadoro G, 2007. The involvement of auxin in the ripening of climacteric fruits comes of age: The hormone plays a role of its own and has an intense interplay with ethylene in ripening peaches. J Exper Bot, 58(12): 3299-3308.

United Nations, Food and Agricultural Organization, Statistics Division, 2018. Production of peaches and nectarines in 2016; Crops/Regions/World/Production Quantity (from pick lists) . Retrieved 5 March 2018.

Wright S, 1921. Correlation and causation. J Agric Res, 20(7): 557-585.

Ziosi V, Bregoli AM, Fiori G, Noferini M, Costa G, 2007. 1-MCP effects on ethylene emission and fruit quality traits of peaches and nectarines. Advances in Plant Ethylene Research. p. 167-174.

\footnotetext{
Citation: Ighbareyeh JMH, Ighbareyeh MMH, Suliemieh SAA, Daraweesh A-Q, Cano Carmona E, Cano Ortiz A, 2019. Peach (Prunus persica L. Batsch) production and environmental conditions in Jenin, Palestine. Net J Agric Sci, 7(2): 78-84.
} 